BRAVILLIAN JOURNAL

www.bjournal.com.br
ISSN 0100-879X

Volume 43 (4) 268-380 April 2011

BIOMEDICAL SCIENCES

AND

CLINICAL INVESTIGATION

Braz J Med Biol Res, April 2011, Volume 44(4) 366-373

doi: 10.1590/S0100-879X2011007500020

Psychopharmacotherapy of panic disorder: 8-week randomized trial with clonazepam and paroxetine

A.E. Nardi, A.M. Valença, R.C. Freire, M.D. Mochcovitch, R. Amrein, A. Sardinha1, M.N. Levitan, I. Nascimento, V.L. de-Melo-Neto, A.L. King, A.C. de O. e Silva, A.B. Veras, G.P. Dias, G.L. Soares-Filho, R.T. da Costa, M.A. Mezzasalma1, M.R. de Carvalho, A.C. de Cerqueira, J.E. Hallak, J.A. Crippa and M. Versiani

The Brazilian Journal of Medical and Biological Research is partially financed by

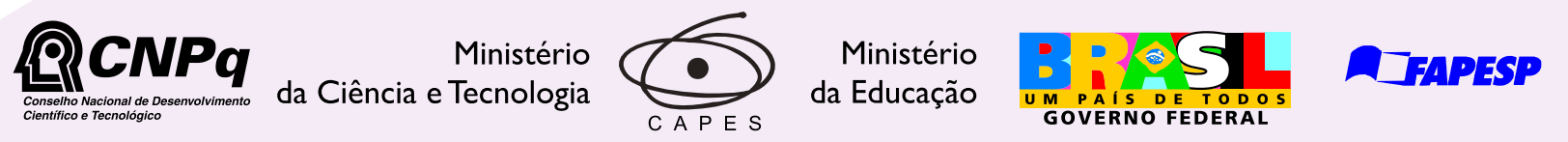

Institutional Sponsors
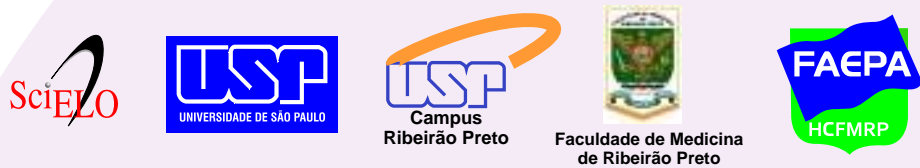

Ministério
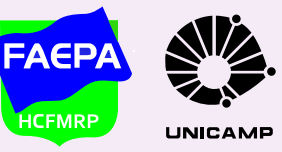

Ф SHIMADZU

GE Healthcare
Hotsite of proteomics metabolomics developped by:

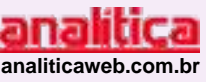

Thermo 


\title{
Psychopharmacotherapy of panic disorder: 8-week randomized trial with clonazepam and paroxetine
}

\author{
A.E. Nardi ${ }^{1}$, A.M. Valença ${ }^{1,3}$, R.C. Freire ${ }^{1}$, M.D. Mochcovitch ${ }^{1}$, R. Amrein ${ }^{1}$, \\ A. Sardinha1 ${ }^{1}$, M.N. Levitan ${ }^{1}$, I. Nascimento ${ }^{1}$, V.L. de-Melo-Neto1,4, A.L. King1, \\ A.C. de O. e Silva ${ }^{1,3}$, A.B. Veras ${ }^{1}$, G.P. Dias ${ }^{1,2}$, G.L. Soares-Filho ${ }^{1,5}$, \\ R.T. da Costa $^{1}$, M.A. Mezzasalma ${ }^{1}$, M.R. de Carvalho' ${ }^{1}$, A.C. de Cerqueira ${ }^{1}$, \\ J.E. Hallak ${ }^{6}$, J.A. Crippa ${ }^{6}$ and M. Versiani ${ }^{1}$ \\ ${ }^{1}$ Laboratório de Pânico e Respiração, Instituto de Psiquiatria, ${ }^{2}$ Laboratório de Neurobiologia da Retina, \\ Instituto Nacional de Ciência e Tecnologia Translacional em Medicina, \\ Universidade Federal do Rio de Janeiro, Rio de Janeiro, RJ, Brasil \\ ${ }^{3}$ Departamento de Psiquiatria, Faculdade de Medicina, Universidade Federal Fluminense, Niterói, RJ, Brasil \\ ${ }^{4}$ Departamento de Psiquiatria, Faculdade de Medicina, Universidade Federal de Alagoas, Maceió, AL, Brasil \\ 5 Unidade de Interconsulta Psiquiátrica, Hospital Pró-Cardíaco, Rio de Janeiro, RJ, Brasil \\ ${ }^{6}$ Departamento de Neurociência e Comportamento, Faculdade de Medicina de Ribeirão Preto, \\ Universidade de São Paulo, Ribeirão Preto, SP, Brasil
}

\begin{abstract}
The objective of the present randomized, open-label, naturalistic 8-week study was to compare the efficacy and safety of treatment with clonazepam $(\mathrm{N}=63)$ and paroxetine $(\mathrm{N}=57)$ in patients with panic disorder with or without agoraphobia. Efficacy assessment included number of panic attacks and clinician ratings of the global severity of panic disorders with the clinical global impression (CGI) improvement (CGI-I) and CGI severity (CGI-S) scales. Most patients were females $(69.8$ and $68.4 \%$ in the clonazepam and paroxetine groups, respectively) and age (mean \pm SD) was $35.9 \pm 9.6$ years for the clonazepam group and $33.7 \pm 8.8$ years for the paroxetine group. Treatment with clonazepam versus paroxetine resulted in fewer weekly panic attacks at week 4 (0.1 vs 0.5, respectively; P < 0.01), and greater clinical improvements at week 8 (CGI-I: 1.6 vs 2.9 ; P = 0.04). Anxiety severity was significantly reduced with clonazepam versus paroxetine at weeks 1 and 2, with no difference in panic disorder severity. Patients treated with clonazepam had fewer adverse events than patients treated with paroxetine $(73$ vs $95 \%$; $\mathrm{P}=$ 0.001). The most common adverse events were drowsiness/fatigue (57\%), memory/concentration difficulties (24\%), and sexual dysfunction (11\%) in the clonazepam group and drowsiness/fatigue (81\%), sexual dysfunction (70\%), and nausea/vomiting $(61 \%)$ in the paroxetine group. This naturalistic study confirms the efficacy and tolerability of clonazepam and paroxetine in the acute treatment of patients with panic disorder.
\end{abstract}

Key words: Paroxetine; Clonazepam; Panic disorder; Efficacy; Safety

\section{Introduction}

Panic disorder is a chronic debilitating illness characterized by severe, recurrent, spontaneous panic attacks with autonomic symptoms, with a lifetime prevalence rate of $5 \%$ (1). Panic disorder, both with and without agoraphobia, can be profoundly physically and emotionally disabling for affected individuals, and is associated with substantial costs to society (2-5). The disease has several adverse psychological consequences, including poor general medical and emotional health, increased risk of alcohol abuse, marital and occupational dysfunction, greater use of medication, increased emergency room use, with up to $20 \%$ of sufferers attempting suicide (2).

Pharmacotherapy is effective in the treatment of panic disorder compared with placebo (6-8); however, it is problematic for several reasons. Despite pharmacotherapy, $20-40 \%$ of patients with panic disorder in clinical trials

Correspondence: A.E. Nardi, Laboratório de Pânico e Respiração, Instituto de Psiquiatria, UFRJ, INCT-TM (CNPq), Rua Visconde de Piraja, 407/702, 22410-003 Rio de Janeiro, RJ, Brasil. Fax: +55-21-2523-6839. E-mail: antonionardi@terra.com.br

Received August 16, 2010. Accepted February 3, 2011. Available online February 18, 2011. Published April 11, 2011. 
remain symptomatic and this proportion may be higher in the naturalistic setting (9). In addition, the subtype of panic disorder (respiratory or non-respiratory) can influence the response to pharmacotherapy and affect outcomes (1012). Furthermore, discontinuation of pharmacotherapy can lead to withdrawal symptoms and a significant number of panic disorder patients suffer relapse flowing cessation of treatment $(13,14)$.

Benzodiazepines $(6,8,14)$ and selective serotonin reuptake inhibitors (SSRIs) $(8,15)$ are two drug classes with proven efficacy in treating panic disorder. In a metaanalysis of 53 studies including 7725 patients with panic disorder who received pharmacotherapeutic treatment, the benzodiazepines and SSRIs showed comparable efficacy (7). SSRIs have been prescribed for panic disorder with or without agoraphobia for over a decade and are recommended as first-line treatment for panic disorder on the basis of their favorable safety profile (16). The efficacy and safety profile of the SSRI paroxetine has been demonstrated in the treatment of panic disorder in a number of randomized controlled trials (17-19). However, the benzodiazepines remain one of the most commonly prescribed therapeutic options for panic disorder (20).

Benzodiazepines are rapidly acting, effective, well tolerated and suitable as monotherapy $(11,21)$ or combination therapy (22). Clonazepam also affects serotonin transmission $(23,24)$ and is the only benzodiazepine on the market for which additional serotonergic activity has been shown, an action that may contribute to its ansiolytic effects (23-25). Benzodiazepines and SSRIs are associated with different adverse event $(A E)$ profiles $(6,14)$. When patients with panic disorder cannot tolerate the AEs associated with a particular drug class, switching to a different drug class can improve the safety outcomes of panic disorder $(6,26)$. Accordingly, which drug to prescribe depends largely on considerations of AE profiles (6).

Although SSRIs and benzodiazepines have been shown to have comparable efficacy in the treatment of panic disorder in a meta-analysis (7), there have been few direct comparisons in clinical trials. Double-blind, placebocontrolled studies have demonstrated the efficacy and safety of clonazepam and of paroxetine individually, but direct comparisons between these drugs have not been made. Therefore, the objective of this study was to compare the efficacy and safety of 8 weeks of treatment with clonazepam and paroxetine in patients with panic disorder in a naturalistic setting, using a randomized, open-label study design. Although the open design has its limitations, it permits careful individual dose adaptation as is done in clinical practice.

\section{Material and Methods}

\section{Study design \\ The study protocol was approved by the Ethics Commit-}

tee of the Instituto de Psiquiatria, Universidade Federal do Rio de Janeiro, Rio de Janeiro, RJ, Brazil. Written informed consent was obtained from all patients prior to inclusion.

This was a naturalistically designed, prospective, randomized, open-label study. For patients on prior anti-panic medication a 1-week wash-out period was employed, except for those taking fluoxetine for whom a 6-week washout period was used. Patients were initially randomized to receive either $0.5-2$ clonazepam or $10-40 \mathrm{mg} /$ day paroxetine, taken after dinner. The planned starting dose was 0.5-1 mg/day clonazepam and $10 \mathrm{mg} /$ day paroxetine. Maintenance doses of $2 \mathrm{mg}$ clonazepam and $40 \mathrm{mg}$ paroxetine were planned to be achieved at the end of the second treatment week, but patients were still kept in the study if these doses were not achieved due to AEs. For every 4 patients entering the trial, two were randomly assigned to clonazepam and two to paroxetine. Neither the patient nor the treating physician had any influence on the drug taken. Treatment was given for 8 weeks and dose adjustment was permitted according to the patient's symptoms. Clonazepam and paroxetine were chosen for comparison since both are approved for the treatment of panic disorder in Brazil. Generic and branded versions of both drugs are available in Brazil and cost is generally low, which makes their relative efficacy and safety an important factor in the choice of treatment.

\section{Patients}

Patients were evaluated in the Panic and Respiration Laboratory of the Institute of Psychiatry, Rio de Janeiro, Brazil. Participants were male and female patients aged 18-60 years who met the Diagnostic and Statistical Manual of Mental Disorders, Fourth Edition, text revision criteria for panic disorder, with or without agoraphobia, as determined by a structured clinical interview. Patients were also required to have at least two panic attacks in the week preceding their inclusion in the study. Patients were excluded if they were unable or unwilling to provide written informed consent, did not complete all the evaluations before study initiation, or if they were diagnosed with comorbidities that could affect clinical evaluation including drug abuse, neurological disorders, or severe personality disorder.

\section{Outcome measures}

The rating was performed by independent examiners who were blind to the drugs under study. Demographic and clinical features at baseline were compared between groups. Efficacy parameters were recorded at baseline and at weeks 1, 2, 4, and 8. Efficacy assessments included the number of panic attack and clinician ratings of the global severity of panic disorder using the clinical global impression (CGI) and severity (CGI-S) scale. Scores ranged from 1 (not at all ill) to 7 (extremely ill). Global change from the baseline assessment was also rated with the CGI improvement (CGI-I) scale. Scores ranged from 1 (very much improved) to 7 (very much worse). Severity of anxiety was assessed using the 
Hamilton Anxiety Rating Scale (HAMA) 14-item test.

Regarding safety parameters, a physical examination was performed on day 1 of treatment and at the end of the treatment period or at study discontinuation. Blood pressure and heart rate were measured at every visit. A 12-lead electrocardiogram and laboratory tests (i.e., hematology, chemistry, urinalysis) were obtained at baseline and at week 8 . AEs were recorded at baseline and at each defined time during treatment by independent examiners who were blind to the study drugs. AE data were collected by asking about spontaneous complaints and by a subsequent systematic inquiry using a list of AEs that were combined with the Benzodiazepine Discontinuation Symptom Scale (27). The severity of each AE was also recorded; multiple episodes of the same AE were counted only once, but they were rated at the greatest level of severity.

\section{Statistical analysis}

All patients who took at least one dose were included in the final analysis. Patient responses were analyzed based on an intent to treat, last value carried forward approach. Appropriate parametric and non-parametric tests were employed; the Student $t$-test for independent samples were used for HAMA and for the number of panic attacks. The Cochran-Armitage $X^{2}$ test for linear trends was employed for CGI-I and CGI-S. The statistical analyses were twotailed and $5 \%$ was considered to be significant.

\section{Results}

\section{Overall}

A total of 120 patients met the inclusion criteria; 63 were randomized to receive clonazepam and 57 to receive paroxetine. One patient in the clonazepam group and seven patients in the paroxetine group withdrew consent before the first drug intake. These patients had been included in the randomization process but were not considered in the total number of patients. Patient demographics and clinical characteristics were similar for the two groups, with no statistically significant differences between groups for any of the parameters studied (Table 1). Most patients were females $(69 \%)$, were educated at least to high school level (63\%), and were employed $(66 \%)$. Most patients included had panic disorder plus agoraphobia (93\%) and had not received prior therapy $(63 \%)$. The high proportion of patients suffering from agoraphobia was due to patients with a long history of panic disorder and agoraphobia often being referred to our institute. Of 44 patients with prior therapy, 1 patient in the paroxetine group had failed treatment previously with an SSRI and no patients in the clonazepam group had failed with a benzodiazepine. The mean ( \pm SD) initial dose was $0.97 \pm 0.1 \mathrm{mg} /$ day in the clonazepam group and $10.5 \pm 2.3 \mathrm{mg} /$ day in the paroxetine group. At week 8 , the mean dose was $1.92 \pm 0.3 \mathrm{mg} /$ day in the clonazepam group and $38.4 \pm 3.7 \mathrm{mg} /$ day in the paroxetine group. Two patients who received paroxetine and 1 patient who received clonazepam withdrew from the study at the end of the first month as a result of poor efficacy; all other patients participated until the end of the 8-week study.

A 1-week wash-out period was included to remove prior anti-panic medication. Less than $25 \%$ of the patients in each group were taking anti-panic medication one week before staring the trial $(24.6 \%$ in the paroxetine group and $12.7 \%$ in the clonazepam group). There was no significant difference in the number of panic attacks, CGI, or AEs reported by these patients at screening and at baseline.

\section{Efficacy}

After initiation of drug treatment there was a dramatic decrease in the number of weekly panic attacks in both treatment groups, which persisted over the course of the treatment period (Figure 1). At week 4, patients in the clonazepam group had significantly fewer panic attacks $(0.1 \pm 0.5$ per week) than those in the paroxetine group $(0.5 \pm 0.9$ per week; $P<0.01$; Table 2$)$. At week 8 , patients experienced similarly low numbers of panic attacks with clonazepam and paroxetine $(0.2 \pm 0.6$ vs $0.2 \pm 0.4$ per week, respectively; $\mathrm{P}=$ not significant). The two groups showed a similar average reduction of panic attacks over

Table 1. Patient baseline demographics and clinical characteristics.

\begin{tabular}{lcc}
\hline & Clonazepam & Paroxetine \\
\hline Number of patients & 63 & 57 \\
Age [years (mean \pm SD)] & $35.9 \pm 9.6$ & $33.7 \pm 8.8$ \\
Gender & & \\
$\quad$ Female & $44(69.8)$ & $39(68.4)$ \\
$\quad$ Male & $19(30.2)$ & $18(31.6)$ \\
Education & & \\
$\quad$ High school or less & $25(39.7)$ & $20(35.1)$ \\
$\quad$ College or more & $38(60.3)$ & $37(64.9)$ \\
Marital status & & \\
$\quad$ Married & $33(52.4)$ & $29(50.9)$ \\
$\quad$ Not married & $30(47.6)$ & $28(49.1)$ \\
Employment status & $39(61.9)$ & $40(70.2)$ \\
$\quad$ Employed & $24(38.1)$ & $17(29.8)$ \\
$\quad$ Unemployed & & \\
Diagnosis & $4(6.3)$ & $5(8.8)$ \\
$\quad$ Panic disorder without agoraphobia & $59(93.7)$ & $52(91.2)$ \\
$\quad$ Panic disorder with agoraphobia & & \\
Previous therapy & $23(36.5)$ & $21(36.8)$ \\
$\quad$ Yes & $40(63.5)$ & $36(63.2)$ \\
$\quad$ No & $73.55 \pm 9.04$ & $71.7 \pm 8.96$ \\
Weight [kg (mean \pm SD)] & & \\
\hline
\end{tabular}

Data are reported as number of patients with percent in parentheses, unless otherwise stated. 

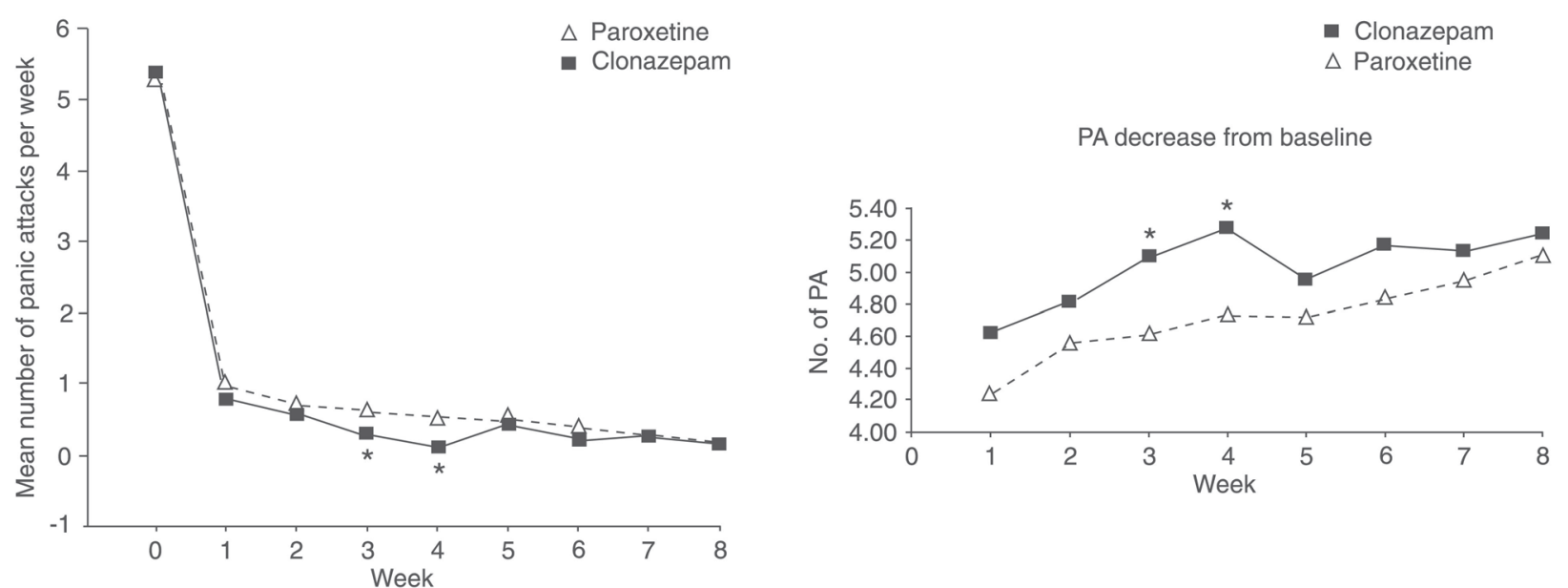

Figure 1. Number of panic attacks (PA) experienced by patients receiving clonazepam or paroxetine. ${ }^{*} \mathrm{P}<0.05$ compared to paroxetine $(t$-test).

Table 2. Summary of efficacy variables at baseline and at weeks 1, 2, 4, and 8 .

\begin{tabular}{|c|c|c|c|c|}
\hline \multirow[t]{2}{*}{ Efficacy variable } & \multicolumn{2}{|c|}{ Clonazepam $(\mathrm{N}=63)$} & \multicolumn{2}{|c|}{ Paroxetine $(\mathrm{N}=57)$} \\
\hline & Mean \pm SD & Range (min-max) & Mean \pm SD & Range (min-max) \\
\hline \multicolumn{5}{|l|}{ Baseline } \\
\hline No. of panic attacks per month & $5.4 \pm 2.6$ & $3-14$ & $5.3 \pm 2.3$ & $3-14$ \\
\hline CGI-I & - & - & - & - \\
\hline CGI-S & $4.5 \pm 0.5$ & $4-5$ & $4.3 \pm 0.5^{*}$ & $4-5$ \\
\hline HAMA & $11.9 \pm 2.4$ & $7-16$ & $11.5 \pm 2.7$ & $6-16$ \\
\hline \multicolumn{5}{|l|}{ Week 1} \\
\hline No. of panic attacks per week & $0.8 \pm 1.1$ & $0-6$ & $1.0 \pm 1.3$ & $0-4$ \\
\hline CGI-I & $2.2 \pm 0.8$ & $1-4$ & $2.7 \pm 1.0^{* *}$ & $1-5$ \\
\hline CGI-S & $2.2 \pm 1.1$ & $1-5$ & $2.5 \pm 1.2$ & $1-5$ \\
\hline HAMA & $10.0 \pm 3.5$ & $3-19$ & $12.2 \pm 4.2^{* *}$ & $6-20$ \\
\hline \multicolumn{5}{|l|}{ Week 2} \\
\hline No. of panic attacks per week & $0.6 \pm 1.0$ & $0-5$ & $0.7 \pm 1.1$ & $0-8$ \\
\hline CGI-I & $2.2 \pm 1.0$ & $1-5$ & $2.7 \pm 1.2^{* *}$ & $1-5$ \\
\hline CGI-S & $2.1 \pm 1.2$ & $1-6$ & $2.5 \pm 1.3$ & $1-5$ \\
\hline HAMA & $11.1 \pm 3.4$ & $5-21$ & $12.7 \pm 3.4^{*}$ & $6-21$ \\
\hline \multicolumn{5}{|l|}{ Week 4} \\
\hline No. of panic attacks per week & $0.1 \pm 0.5$ & $0-3$ & $0.5 \pm 0.9^{* *}$ & $0-4$ \\
\hline No. of patients with $\leq 1$ panic attack during previous month & $43(68 \%)$ & & $35(61 \%)$ & \\
\hline CGI-I & $2.0 \pm 1.1$ & $1-4$ & $2.2 \pm 1.2$ & $1-5$ \\
\hline CGI-S & $2.0 \pm 1.0$ & $1-4$ & $2.2 \pm 1.3$ & $1-5$ \\
\hline HAMA & $11.8 \pm 3.7$ & $5-18$ & $11.4 \pm 4.3$ & $5-20$ \\
\hline \multicolumn{5}{|l|}{ Week 8} \\
\hline No. of panic attacks per week & $0.2 \pm 0.6$ & $0-3$ & $0.2 \pm 0.4$ & $0-1$ \\
\hline No. of patients with $\leq 1$ panic attack during previous month & $49(78 \%)$ & & $39(68 \%)$ & \\
\hline CGI-I & $1.6 \pm 1.0$ & $1-5$ & $2.9 \pm 1.2^{*}$ & $1-5$ \\
\hline CGI-S & $1.6 \pm 1.0$ & $1-5$ & $1.9 \pm 1.2$ & $1-5$ \\
\hline HAMA & $10.5 \pm 3.9$ & $3-21$ & $10.4 \pm 3.7$ & $3-20$ \\
\hline
\end{tabular}

CGI-I = clinical global impression - improvement; CGI-S = clinical global impression - severity; HAMA = Hamilton Anxiety Rating Scale. CGI-I values are related to baseline. ${ }^{*} \mathrm{P}<0.05$ and ${ }^{* *} \mathrm{P}<0.001$ based on $t$-tests for HAMA and number of panic attacks, and on Cochran-Armitage tests for CGI-I and CGI-S. 
the first 8 weeks of treatment (Figure 1). The proportion of patients who were panic free following treatment is presented in Figure 2. At week 4, more patients who received clonazepam were free of panic attacks (92.06 vs $70.16 \%$, respectively; $\mathrm{P}=0.002$ ).

Clonazepam had a faster onset of action than paroxetine. When CGI-I was assessed, patients treated with clonazepam had significantly greater improvements than those treated with paroxetine at week 1 (2.2 \pm 0.8 vs 2.7 $\pm 1.0 ; \mathrm{P}=0.003)$ and week 2 (2.2 \pm 1.0 vs $2.7 \pm 1.2 ; \mathrm{P}=$ 0.006 ; Table 2). CGI-I was further reduced over the course of the study, with values of $1.6 \pm 1.0$ for clonazepam and $2.9 \pm 1.2$ for paroxetine $(P=0.04)$ at week 8 . At baseline, the severity of panic disorder as measured by CGI-S was borderline significantly higher in patients randomized to receive clonazepam versus paroxetine $(4.5 \pm 0.5$ vs $4.3 \pm 0.5$ $\mathrm{P}=0.02$; Table 2). After 4 weeks of treatment, there was no

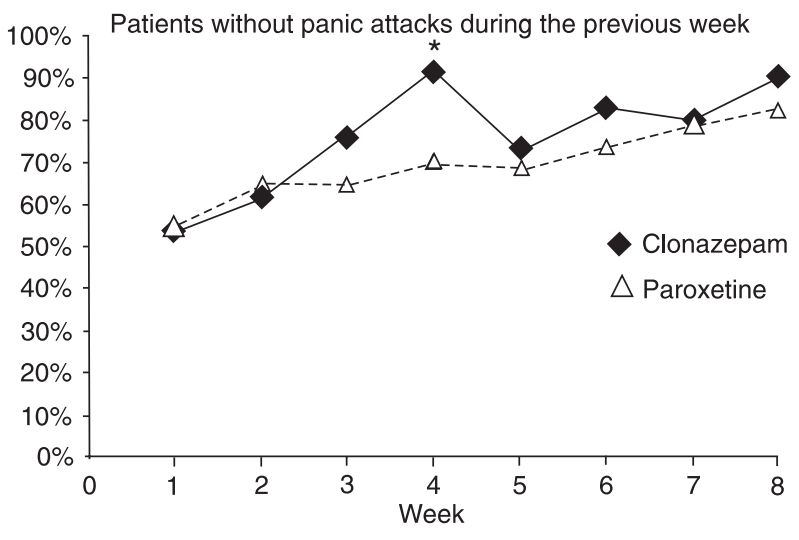

Figure 2. Proportion of patients who were free of panic attacks following treatment with clonazepam or paroxetine. ${ }^{*} \mathrm{P}<0.05$ compared to paroxetine (Fischer exact test).

Table 3. Summary of adverse events (AE) at week 8.

\begin{tabular}{|c|c|c|c|c|c|c|c|c|c|c|c|}
\hline \multirow[t]{3}{*}{ Safety variable } & \multicolumn{5}{|c|}{ Clonazepam ( $\mathrm{N}=63)$} & \multicolumn{5}{|c|}{ Paroxetine $(\mathrm{N}=57)$} & \multirow[t]{3}{*}{$\mathrm{P}$} \\
\hline & \multirow{2}{*}{$\frac{\text { Before treatment }^{\dagger}}{\text { Overall }}$} & \multicolumn{4}{|c|}{ During treatment } & \multirow{2}{*}{$\frac{\text { Before treatment }^{\dagger}}{\text { Overall }}$} & \multicolumn{4}{|c|}{ During treatment } & \\
\hline & & Overall & Mild & Moderate & Severe & & Overall & Mild & Moderate & Severe & \\
\hline Patients with $\mathrm{AE}$ & $40(63.5)$ & $46(73.0)$ & & & & $37(64.9)$ & $54(94.7)$ & & & & ** \\
\hline \multicolumn{12}{|l|}{ AEs } \\
\hline Drowsiness/fatigue & 0 & $36(57)$ & 30 & 6 & & 0 & $46(81)$ & 34 & 12 & & ** \\
\hline Sexual dysfunction & $8(13)$ & $7(11)$ & 7 & & & $8(14)$ & $40(70)$ & 25 & 14 & 1 & ** \\
\hline Memory/concentration difficulties & $22(35)$ & $15(24)$ & 15 & & & $12(21)$ & $23(40)$ & 22 & 1 & & * \\
\hline Nausea/vomiting & $13(21)$ & 0 & & & & $6(11)$ & $35(61)$ & 23 & 12 & & ** \\
\hline Appetite/weight change & 0 & $1(2)$ & 1 & & & $1(2)$ & $31(54)$ & 19 & 12 & & ** \\
\hline Dry mouth & $1(2)$ & 0 & & & & $2(4)$ & $27(47)$ & 27 & & & ** \\
\hline Excessive sweating & $2(3)$ & 0 & & & & 0 & $18(32)$ & 17 & 1 & & ** \\
\hline Diarrhea/constipation & 0 & 0 & & & & 0 & $15(26)$ & 15 & & & ** \\
\hline Shaking/trembling/tremor & $29(46)$ & 0 & & & & $24(42)$ & $14(25)$ & 14 & & & ** \\
\hline Headache & $22(35)$ & 0 & & & & $15(21)$ & $4(7)$ & 4 & & & \\
\hline Derealization & 0 & 0 & & & & 0 & $2(4)$ & 2 & & & \\
\hline Anxiety/irritability & $35(56)$ & 0 & & & & $34(60)$ & $1(2)$ & 1 & & & \\
\hline Paresthesia & $21(33)$ & 0 & & & & $19(33)$ & $1(2)$ & 1 & & & \\
\hline Metallic taste & 0 & $1(2)$ & 1 & & & 0 & 0 & & & & \\
\hline Insomnia, nightmare & $29(46)$ & 0 & & & & $25(44)$ & 0 & & & & \\
\hline Weakness & $20(32)$ & $6(10)$ & 6 & & & $12(21)$ & $7(12)$ & 6 & 1 & & \\
\hline Tachycardia/palpitations & $1(2)$ & 0 & & & & $3(5)$ & 0 & & & & \\
\hline Muscle aches/stiffness & 0 & 0 & & & & $1(2)$ & 0 & & & & \\
\hline Depersonalization & 0 & 0 & & & & $3(5)$ & 0 & & & & \\
\hline Dizziness/lightheadedness & $2(3)$ & 0 & & & & $2(4)$ & 0 & & & & \\
\hline Blurred/double vision & $1(2)$ & 0 & & & & 0 & 0 & & & & \\
\hline Tinnitus & $1(2)$ & 0 & & & & $1(2)$ & 0 & & & & \\
\hline
\end{tabular}

Data are reported as number of patients with percent in parentheses. AEs were included if they were present at least once during the 8 -week treatment period, and multiple occurrences in 1 patient were only counted once, at the highest degree of severity. ${ }^{\dagger} \mathrm{AEs}$ occurring during the last 4 weeks before baseline; AEs at baseline did not differ significantly in frequency between groups. ${ }^{*} \mathrm{P}<0.05$, ${ }^{* *} \mathrm{P}<$ 0.001 ( $X^{2}$ test). 
significant difference between groups; CGI-S was reduced to $2.0 \pm 1.0$ in the clonazepam group and to $2.2 \pm 1.3$ in the paroxetine group. At week $8, \mathrm{CGI}-\mathrm{S}$ was $1.6 \pm 1.0$ in the clonazepam group and $1.9 \pm 1.2$ in the paroxetine group ( $P=$ not significant). In agreement with $\mathrm{CGI}-\mathrm{I}$, the severity of anxiety measured by HAMA at week 1 was significantly lower in clonazepam-treated patients $(10.0 \pm 3.5)$ than in paroxetine-treated patients $(12.2 \pm 4.2 ; P=0.003$; Table 2$)$. Significant reductions in the clonazepam group versus the paroxetine group were also observed at week $2(P=0.03)$, but not at week 4 or at the end of the study $(10.5 \pm 3.9$ and $10.4 \pm 3.7$, respectively).

\section{Safety}

No patients withdrew because of AEs. More than $60 \%$ of patients enrolled in the trial reported AEs at baseline, regardless of the study group, and these were mainly anxiety, insomnia, headache, shaking/trembling, paresthesia, memory/concentration difficulties, nausea/vomiting, sexual dysfunction, and weakness (Table 3).

Patients treated with clonazepam had significantly fewer AEs than patients treated with paroxetine at week 8 (73.0 versus $94.7 \%$, respectively; $P=0.001$; Table 3 ). The most common AEs in the clonazepam group were drowsiness/ fatigue $(57 \%)$, memory/concentration difficulties (24\%), and sexual dysfunction (11\%). The vast majority of AEs in clonazepam-treated patients were of mild severity, with moderate severity reported for 6 cases of drowsiness/ fatigue. The most common AEs in the paroxetine group were drowsiness/fatigue (81\%), sexual dysfunction (70\%), and nausea/vomiting (61\%). Although most AEs in the paroxetine group were of mild severity, there were several cases of moderately severe drowsiness/fatigue, sexual dysfunction, nausea/vomiting, and appetite/weight change. A severe case of sexual dysfunction was also noted with paroxetine. AEs that occurred significantly more frequently in the paroxetine group versus the clonazepam group were drowsiness/fatigue $(P=0.006)$, sexual dysfunction, nausea/ vomiting, appetite/weight change, dry mouth, excessive sweating, diarrhea/constipation, and shaking/trembling/ tremor (all $P<0.001$ ). There were no clinically significant changes in laboratory parameters in either group during the study.

\section{Discussion}

The present investigation confirms earlier studies, which have demonstrated the efficacy of clonazepam $(11,12,21,28-30)$ and paroxetine $(18,19,31,32)$ in separate trials in the treatment of panic disorder. The present study compares clonazepam with paroxetine using a parallel methodology with the same team of health providers. There was a small difference in effectiveness in favor of clonazepam between the two treatments. As assessed by CGI-I scores, clonazepam was associated with significantly greater clini- cal improvement than paroxetine at the end of the 8-week treatment period. Furthermore, clonazepam was associated with a faster response than paroxetine. Although the number of panic attacks experienced was similarly reduced in both treatment groups by week 8 , both CGI-I and HAMA scores were significantly better in clonazepam-treated patients than in paroxetine-treated patients at weeks 1 and 2 . The slower onset of action of paroxetine is consistent with other studies of paroxetine and other SSRIs, and is often associated with increased agitation and anxiety at the beginning of treatment $(14,33)$. Saeki et al. (34) demonstrated that genetic and pharmacokinetic factors may affect the initial therapeutic response to paroxetine (34). Plasma concentration of paroxetine, serotonin transporter gene-linked polymorphic region (5-HTTLPR) genotype, and co-morbid physical illness were significant factors affecting the initial pharmacotherapeutic effect of paroxetine in Japanese patients (34). In contrast to SSRIs, benzodiazepines are associated with a rapid onset of action (22,35). An SSRI can take 4-6 weeks to become entirely effective, but a benzodiazepine may be combined with an SSRI at the beginning of therapy to overcome this delay, and initial studies have confirmed the suitability of this approach $(16,32,36)$.

An original methodological feature of this trial was the systematic evaluation of AEs prior to as well as during treatment. This allowed us to differentiate drug-induced AEs from pre-existing drug-independent conditions, revealing a completely new picture for some of the reported AEs. Several complaints, typically regarded as AEs, were already frequent before treatment and both investigational products were successful not only in reducing the frequency of panic attacks, but also some of the pre-existing panic attack symptoms such as anxiety, paresthesia, insomnia, weakness, headache, and shaking/trembling. Notably, clonazepam reduced the frequency of nausea/vomiting and memory and concentration difficulties, whereas these events became more frequent under paroxetine. Likewise, clonazepam had no effect on preexisting sexual activity, whereas paroxetine increased the frequency of sexual dysfunction. Both products were associated with drowsiness and/or fatigue. Whereas paroxetine was associated with appetite/weight change, dry mouth, excessive sweating and diarrhea/constipation, clonazepam did not have such effects. To summarize, in this short-term investigation of safety, almost all patients treated with paroxetine experienced AEs compared with three-quarters of patients treated with clonazepam. Furthermore, there were more cases of moderately severe and severe AEs in the paroxetine group versus the clonazepam group.

The AEs reported for clonazepam are typical of those expected from a highly potent benzodiazepine, and consistent with the safety profile of clonazepam observed in other studies $(11,22,30)$. The most frequently reported AEs were drowsiness and lapse in memory/concentration. In memory tests, delayed recall rather than immediate recall 
was affected by benzodiazepine treatment, and the effect lasted for a short timeframe after administration (22). The AEs observed with paroxetine in the present analysis are consistent with other studies of SSRIs (37). In addition to the drowsiness/fatigue, sexual dysfunction and memory impairment that occurred or persisted with both agents, paroxetine treatment was commonly associated with AEs such as nausea/vomiting, dry mouth, excessive sweating, diarrhea/constipation and tremor/shaking, which were not experienced by any clonazepam-treated patients. In addition, over half of all patients who received paroxetine experienced appetite/weight change compared with only one patient treated with clonazepam.

One of the limitations of this study was the open-label design. Although the open design has its limitations, it allows for careful individual dose adaptation and was also chosen to permit continuation of the study with long-term treatment. Our sample also does not permit generalization of the results. The trial was conducted at a university research center specialized in anxiety and mood disorders. For example, our sample had a high percentage of high school or more education, which is different from the general Brazilian population. The flexible dose design of the study precludes any dose-response findings. Patients with panic disorder are especially sensitive to pharmacotherapy at the initiation of therapy, and many patients begin on half-doses (14). Clonazepam was started at 0.5 or $1 \mathrm{mg} / \mathrm{day}$ in the present study; however, all patients in both groups reached the full dose by 8 weeks of treatment.

The present acute study cannot address several important problems that are linked to long-term use of the two drugs. This issue shall be addressed in a continuation study lasting 3 years and followed by drug discontinuation. During long-term use, SSRIs may cause weight gain and sexual dysfunction, primarily anorgasmia and ejaculatory dysfunction $(17,38,39)$, and benzodiazepine therapy in panic disorder may lead to abuse or misuse and physical

\section{References}

1. Bienvenu OJ. Lifetime prevalence of panic disorder is about 5\% in the USA. Evid Based Ment Health 2006; 9: 114.

2. Hirschfeld RM. Panic disorder: diagnosis, epidemiology, and clinical course. J Clin Psychiatry 1996; 57 (Suppl 10): 3-8.

3. Mendlowicz MV, Stein MB. Quality of life in individuals with anxiety disorders. Am J Psychiatry 2000; 157: 669-682.

4. Mogotsi M, Kaminer D, Stein DJ. Quality of life in the anxiety disorders. Harv Rev Psychiatry 2000; 8: 273-282.

5. Waghorn G, Chant D, White P, Whiteford H. Disability, employment and work performance among people with ICD-10 anxiety disorders. Aust N Z J Psychiatry 2005; 39: 55-66.

6. Marchesi $\mathrm{C}$. Pharmacological management of panic disorder. Neuropsychiatr Dis Treat 2008; 4: 93-106.

7. Mitte K. A meta-analysis of the efficacy of psycho- and pharmacotherapy in panic disorder with and without agora- dependence, and withdrawal and rebound symptoms when treatment is discontinued (40). Previous reports indicate a high level of relapse following discontinuation of panic disorder pharmacotherapy $(6,13,14)$. In a study in patients with panic disorder who received paroxetine for 12 months, $17 \%$ of patients experienced one or more panic attacks during the 1-year follow-up period after paroxetine discontinuation (31). The long-term outcomes associated with this study, particularly relapse rates, would be of interest. Acomparative study of longer duration would also prove valuable. Both clonazepam (11) and paroxetine $(17,31)$ have been shown to be effective in the treatment of panic disorder over long follow-up periods in separate trials. In a naturalistic 3-year study of 67 patients with panic disorder, clonazepam had a sustained therapeutic effect over the entire treatment period (11). Similarly, paroxetine was effective when given over a 2-year period to 55 patients with panic disorder, with $0.23 \pm 0.2$ panic attacks per week recorded at the end of the treatment period (31).

To conclude, this naturalistic study confirms the efficacy and tolerability of clonazepam and paroxetine in the acute treatment of patients with panic disorder, with greater clinical improvements, faster onset of action and a more favorable $\mathrm{AE}$ profile observed in clonazepam-treated patients.

\section{Acknowledgments}

We thank Hester van Lier, PhD, of Excerpta Medica who provided editorial/writing support. Research supported by CNPq and INCT Translational Medicine (CNPq). A.E. Nardi, A.M. Valença, I. Nascimento, J.A. Crippa, and M. Versiani are recipients of CNPq productivity fellowship awards. The authors received editorial/writing support solely in the preparation of this manuscript funded by F. Hoffmann-La Roche Ltd. The funding source had no role in the study design, collection, analysis or interpretation of data, nor in the decision to submit the paper for publication. phobia. J Affect Disord 2005; 88: 27-45.

8. Pull CB, Damsa C. Pharmacotherapy of panic disorder. Neuropsychiatr Dis Treat 2008; 4: 779-795.

9. Bandelow B, Ruther E. Treatment-resistant panic disorder. CNS Spectr 2004; 9: 725-739.

10. Nardi AE, Nascimento I, Valenca AM, Lopes FL, Mezzasalma MA, Zin WA, et al. Respiratory panic disorder subtype: acute and long-term response to nortriptyline, a noradrenergic tricyclic antidepressant. Psychiatry Res 2003; 120: 283-293.

11. Nardi AE, Valenca AM, Nascimento I, Lopes FL, Mezzasalma MA, Freire RC, et al. A three-year follow-up study of patients with the respiratory subtype of panic disorder after treatment with clonazepam. Psychiatry Res 2005; 137: 61-70. 
12. Valenca AM, Nardi AE, Mezzasalma MA, Nascimento I, Zin WA, Lopes FL, et al. Therapeutic response to benzodiazepine in panic disorder subtypes. São Paulo Med J 2003; 121: $77-80$.

13. Ballenger JC. Remission rates in patients with anxiety disorders treated with paroxetine. J Clin Psychiatry 2004; 65: 1696-1707.

14. Susman J, Klee B. The role of high-potency benzodiazepines in the treatment of panic disorder. Prim Care Companion $J$ Clin Psychiatry 2005; 7: 5-11.

15. Bakker A, van Balkom AJ, van Dyck R. Selective serotonin reuptake inhibitors in the treatment of panic disorder and agoraphobia. Int Clin Psychopharmacol 2000; 15 (Suppl 2): S25-S30.

16. Practice guideline for the treatment of patients with panic disorder. Work Group on Panic Disorder. American Psychiatric Association. Am J Psychiatry 1998; 155: 1-34.

17. Dannon PN, lancu I, Cohen A, Lowengrub K, Grunhaus L, Kotler M. Three year naturalistic outcome study of panic disorder patients treated with paroxetine. BMC Psychiatry 2004; 4: 16.

18. Pollack MH, Doyle AC. Treatment of panic disorder: focus on paroxetine. Psychopharmacol Bull 2003; 37 (Suppl 1): 53-63.

19. Sheehan DV, Burnham DB, lyengar MK, Perera P. Efficacy and tolerability of controlled-release paroxetine in the treatment of panic disorder. J Clin Psychiatry 2005; 66: 34-40.

20. Bruce SE, Vasile RG, Goisman RM, Salzman C, Spencer $\mathrm{M}$, Machan JT, et al. Are benzodiazepines still the medication of choice for patients with panic disorder with or without agoraphobia? Am J Psychiatry 2003; 160: 1432-1438.

21. Rosenbaum JF, Moroz G, Bowden CL. Clonazepam in the treatment of panic disorder with or without agoraphobia: a dose-response study of efficacy, safety, and discontinuance. Clonazepam Panic Disorder Dose-Response Study Group. J Clin Psychopharmacol 1997; 17: 390-400.

22. Chouinard G. Issues in the clinical use of benzodiazepines: potency, withdrawal, and rebound. J Clin Psychiatry 2004; 65 (Suppl 5): 7-12.

23. Jenner P, Pratt JA, Marsden CD. Mechanism of action of clonazepam in myoclonus in relation to effects on GABA and 5-HT. Adv Neurol 1986; 43: 629-643.

24. Moroz G. High-potency benzodiazepines: recent clinical results. J Clin Psychiatry 2004; 65 (Suppl 5): 13-18.

25. Nardi AE, Perna G. Clonazepam in the treatment of psychiatric disorders: an update. Int Clin Psychopharmacol 2006; 21: 131-142.

26. Zamorski MA, Albucher RC. What to do when SSRIs fail: eight strategies for optimizing treatment of panic disorder. Am Fam Physician 2002; 66: 1477-1484.

27. Nardi AE, Valença AM, Freire RC, Amrein R, Sardinha A, Levitan MN, et al. Randomized open naturalistic acute treat- ment of panic disorder with clonazepam or paroxetine. J Clin Psychopharmacol 2011 (in press).

28. Beauclair L, Fontaine R, Annable L, Holobow N, Chouinard G. Clonazepam in the treatment of panic disorder: a doubleblind, placebo-controlled trial investigating the correlation between clonazepam concentrations in plasma and clinical response. J Clin Psychopharmacol 1994; 14: 111-118.

29. Moroz G, Rosenbaum JF. Efficacy, safety, and gradual discontinuation of clonazepam in panic disorder: a placebocontrolled, multicenter study using optimized dosages. J Clin Psychiatry 1999; 60: 604-612.

30. Valenca AM, Nardi AE, Nascimento I, Mezzasalma MA, Lopes FL, Zin W. Double-blind clonazepam vs placebo in panic disorder treatment. Arq Neuropsiquiatr 2000; 58: 1025-1029.

31. Dannon PN, lancu I, Lowengrub K, Amiaz R, Grunhaus L, Kotler M. Clonazepam augmentation of paroxetine in the treatment of panic disorder: a one year naturalistic followup study. Internet J Ment Health 2005; http://www.ispub. com/journal/the_internet_journal_of_mental_health/archive/ volume_2_number_2_31.html (Accessed: January 5, 2011).

32. Dannon PN, Lowengrub K, lancu I, Kotler M. Paroxetine in panic disorder: clinical management and long-term followup. Expert Rev Neurother 2004; 4: 191-198.

33. American Psychiatric Association. Practice guidelines for the treatment of psychiatric disorders compendium. Arlington: American Psychiatric Press; 2004.

34. Saeki Y, Watanabe T, Ueda M, Saito A, Akiyama K, Inoue $Y$, et al. Genetic and pharmacokinetic factors affecting the initial pharmacotherapeutic effect of paroxetine in Japanese patients with panic disorder. Eur J Clin Pharmacol 2009; 65: 685-691.

35. Andersch S, Rosenberg NK, Kullingsjo H, Ottosson JO, Bech P, Bruun-Hansen J, et al. Efficacy and safety of alprazolam, imipramine and placebo in treating panic disorder. A Scandinavian multicenter study. Acta Psychiatr Scand Suppl 1991; 365: 18-27.

36. Pollack MH, Simon NM, Worthington JJ, Doyle AL, Peters $\mathrm{P}$, Toshkov F, et al. Combined paroxetine and clonazepam treatment strategies compared to paroxetine monotherapy for panic disorder. J Psychopharmacol 2003; 17: 276-282.

37. Marks DM, Park MH, Ham BJ, Han C, Patkar AA, Masand PS, et al. Paroxetine: safety and tolerability issues. Expert Opin Drug Saf 2008; 7: 783-794.

38. Masand PS, Gupta S. Selective serotonin-reuptake inhibitors: an update. Harv Rev Psychiatry 1999; 7: 69-84.

39. Rickels K, Schweizer E. Panic disorder: long-term pharmacotherapy and discontinuation. J Clin Psychopharmacol 1998; 18: 12S-18S.

40. Salzman C. Benzodiazepine treatment of panic and agoraphobic symptoms: use, dependence, toxicity, abuse. $J$ Psychiatr Res 1993; 27 (Suppl 1): 97-110. 